Original Article

\title{
EFFECT OF YOGA THERAPY ON BODY M ASS INDEX AND OXIDATIVE STATUS
}

\author{
Suchetha Kumari N ${ }^{1}$, Damodara Gowda K.M ${ }^{2}$, Sukesh N ${ }^{3}$, Madhu L.N ${ }^{4}$, Kathyayani ${ }^{1}$ \\ ${ }^{1}$ Department of Biochemistry, K.S. Hegde M edical Academy, Nitte University, Karnataka, India - 575 018., ${ }^{2}$ Department of \\ Physiology, K.S. Hegde M edical Academy, Nitte University, Karnataka, India - 575 018., ${ }^{3}$ Dept. of Human Consciousness and \\ Yogic Sciences, M angalore University, M angalagangothri - 574 199, 'Central Research Laboratory, Nitte University, M angalore, \\ Karnataka, India - 575018. \\ Corresponding Author: \\ Suchetha Kumari N \\ Professor, Department of Biochemistry, K.S. Hegde M edical Academy, Nitte University, \\ Karnataka, India - 575 018. E-mail : suchetha.shetty@ rediffmail.com
}

Abstract:

Background and Objective: Human beings are under threat from many chronic diseases and life style disorders. A major cause of all these diseases was found to be improper lifestyle and stress leading to obesity and excessive lipid peroxidation, indicating increased production of reactive oxygen species. Yoga therapy concentrates on purification of body and mind through its integrated holistic approach one can overcome the different kinds of afflictions in life. Hence the present study was undertaken to find out the effect of intervention of yoga therapy in obese individuals.

Materials and Methods: The study was conducted at M RPLladies club auditorium in the M RPL Township after an informed and written consent from all the participants. The research protocol was approved by institutional ethics committee. The study consisted of forty obese male and female subjects. The changes in Body weight, Body M ass Index, Blood sugar, M DA level and Total antioxidant status was estimated before and after one month of yoga therapy. The data obtained was analyzed using paired' $t$ ' test. $p \varangle 0.05$ was the level of significance.

Result: There was a significant decline in the Body Weight $(p=0.020)$, BMI $(p=0.000)$, Fasting Blood Sugar ( $p=0.03$ ) and Post Prandial Blood Sugar $(p=0.000)$ MDA $(p=0.000)$ and significant increase in Total Antioxidant Level $(p=0.021)$ after yoga when compared to that before the yoga therapy.

Conclusion: Yoga therapy is beneficial in maintaining better health by regulating BMI, Oxidative status by improving the biochemical functions of the body and helpful to overcomethe complications of obesity.

Keywords : Body M ass Index, Yoga Therapy, Blood sugar, M DA level, Total Antioxidant.

Runningtitle: "Effect of yoga therapy on obesity".

\section{Introduction}

Obesity is the most hazardous factor found in modern sedentary society and is a complex disorder of the modern world. It is emerged as the most prevalent sedentary lifestyle disorder in urban society. Excessive body weight is associated with various diseases particularly cardiovascular diseases, Type-2 Diabetes Mellitus, Obstructive sleep apnea, certain types of cancer osteoarthritis etc.

Yoga has been shown to be a simple and economical therapeutic modality that may be considered as a beneficial adjuvant for many of the health problems.Yoga therapy is the two fold therapeutic system that prevents and cures various diseases through practice of yoga system. This system concentrates on purification of body and mind, through this integrated holistic approach one can overcome almost all kinds of afflictions in life. It is a kind of low-impact physical exercise, and is used for therapeutic purposes ${ }^{(1,2,3)}$. Yogasanas have been practiced in India from Vedic period and was coordinated and organized in a systematic way, as known today, by Sage Pathanjali. He defined yoga as a systematic practice for purifying one's mind, intellect and body.

In the present scenario, human beings are under threat from many chronic diseases, life style disorders and non communicable diseases etc. A major cause of all these diseases was found to be improper lifestyle and stress. Excessive stress is known to cause hormonal imbalances and chemical imbalances in human body. It disturbs the 
metabolic activities and causes improper coordination of the metabolic and bio-chemical functions. One of the major fallouts of stress in the human body is excessive lipid peroxidation, indicating increased production of reactive oxygen species (ROS). Also during an immune response in the body, there is an increase in the production of ROS which will cause an imbalance in the body between ROS production and antioxidant defenses against the pathogen. Abnormally high levels of peroxidation and the simultaneous decline of antioxidant defense mechanisms can lead to damage of cellular organelles and oxidative stress ${ }^{(4)}$. Hence the natural balance between pro-oxidants and antioxidants will be shifted towards the oxidant side to cause further biological damage. As the oxidative stress increase, cell damage and accumulation of the toxic compounds in the body increases, leading to many pathological conditions.

According to tridosha theory in Ayurveda and Naturopathy literature, namely, Vatha, Pitta and Kapha are the structural and functional factors of the body, which govern the biochemical and physiological activities of the body. These three elements must be in a dynamic equilibrium with each other for the maintenance of health. Any imbalance of their relative equilibrium in the body results in disease. In human body Vatha dosha is responsible for all the physiological activities. Since yoga keeps the balance between ROS production and antioxidant defenses to prevent/ reduce oxidative stress, the present study was undertaken to find out the effect of intervention of yoga therapy in obese individuals.

\section{Materialsand M ethods:}

The present study was conducted to assess the effect of selected yogic practices in obese male and female subjects belong to the age group of $48 \pm 13$ years. The present study involved 40 obese individuals. All the subjects were comparatively new to yogic practices. The study was conducted in MRPL ladies club auditorium in the MRPL Township after an informed and written consent from all the participants. The research protocol was approved by institutional ethics committee. All the individuals were subjected to yoga practices for one month. The yoga practice was performed six days per week between $6 \mathrm{pm}$ to $7 \mathrm{pm}$ under the direct supervision of a trained yoga expert. This practical session utilized a standard sequence of selected Kriya, Asanas, Pranayamas and Relaxation Techniques, taking appropriate precautions for patients like Hypertension and back pain.

The various asanas included in the present study are Swastikasana, Vajrasana, Suptavajrasana, Tadasana, Trikonasana, Parshwakonasana, Paschimotthanasana, Purvotthanasana, Ardhabadha padmasana, Janusirsasana, Mahamudra, Pavanamuktasana, Bhujangasana, Dhanurasana,Viparitakarani and Uttanapadasana. The different pranayama techniques used were Ujjayi, Anuloma viloma and Bhastrika. The kriyas and relaxation techniques were Yoganidra and Agnisara respectively.

The Body Mass Index (BMI) was estimated in all the participants before and after the experimental procedure using the formula, BMI =Weight in $\mathrm{kg} /$ Height in meter'.

For biochemical estimations, about $5 \mathrm{ml}$ of venous blood was collected from all the participants before and after the yoga practice and the serum was used for the estimation of fasting blood sugar, post prandial blood sugar, total antioxidant capacity and lipid peroxidation using commercially available kits.

Statistical Analysis: The data obtained was analyzed for the statistical significance using a paired " $t$ " test . $p \varangle 0.05$ was considered the level of significance.

\section{Results:}

The present study involved the assessment of effect of 
yoga therapy on obesity and oxidative status in obese individuals. The present study showed that the obese individuals reduced their Body Weight, Lipid Peroxidation, Blood Sugar and Total Antioxidant Level. The significant reduction in Body Weight $(p=0.000$, Fig1), BM I ( $p=0.000$, Fig- 2 ), Fasting Blood Sugar ( $p=0.03$, Fig3 ) and post prandial blood sugar ( $p=0.000$, Fig- 4 ) after yoga when compared to that before the yoga therapy. This decline was the clear evidence that one month yoga therapy improved the metabolic and biochemical mechanisms in obese individuals. A significant reduction in the level of M DA ( $p=0.000$, Fig- 5 ) was also recorded in the present study. We also observed a significant increase ( $p=0.021$, Fig- 6 ) in the level of Total Antioxidant after yoga when compared to that before the yoga therapy, which further indicates that one month yoga therapy improves the biochemical and metabolic functions in the body.

\section{Discussion:}

The present study confirmed the positive effects of yoga therapy as a conventional modality of treatment on biochemical imbalances and oxidative status in obese subjects.

Body M ass Index provides a simple numeric measure of a person's "fatness" or "thinness", allowing health professionals to discuss over- and under-weight problems more objectively with their patients. Excessive body weight is associated with various diseases, particularly cardiovascular diseases, Type-2 Diabetes mellitus, Obstructive sleep apnea, certain types of cancer, and osteoarthritis ${ }^{(5)}$. As a result, obesity has been found to reduce life expectancy ${ }^{\left({ }^{(6)}\right.}$. Obesity is most commonly caused by a combination of excessive food intake, lack of physical activity, and genetic susceptibility, although a few cases are caused primarily by genes, endocrine disorders, medications or psychiatric illness. Obesity is one of the leading preventable causes of death worldwide ${ }^{(4,2,7)}$. On an average, obesity reduces life expectancy by six to seven years ${ }^{(5,8)}$; a BMI of $30-35$ reduces life expectancy by two to four years ${ }^{(9)}$ while severe obesity, BMI $>40$ reduces life expectancy by 10 years $^{(10)}$.

The significant reduction in the Body Weight and BM I as recorded in the present study are in line with the earlier studies, wherein, a 6-day yoga program led to decreased body mass index (BM I), waist and hip circumference, fatfree mass, total cholesterol, high-density lipoprotein and fasting serum leptin levels ${ }^{(11)}$, and 12 weeks of yoga led to an overall reduction in food consumption, in eating speed and in food choices ${ }^{(12)}$. Eating disorder symptoms have also decreased following yoga ${ }^{(13)}$, and in those diagnosed with an eating disorder, physical activity increased following yoga, and symptoms decreased, as did BM I and hip and waist measurements ${ }^{(14)}$.

According to yoga, increased body mass is the indication of imbalance in the triguna and tridosha. The root causes of the abnormalities are adhi or mental stress. To overcome the stress the person habituates overeating leading to the deposition of fat in the body. To manage overweight or obesity, one has to reduce the mental stress and has to provide the sufficient physical activities. The practice of yoga can regulate all the body functions in a balanced manner and helpful in providing sustainable health. Analysis of our results clearly indicated that the complications of obesity can be reduced by yoga therapy. The reduction in the body weight might be due to reduction in the deposited fat on adipose tissue.

A reduction in the FBS and PPBS level after the practice of one month yoga indicated the improvement in the biochemical functions in obese individuals. Our findings are similar to the findings of Malhotra et al. who showed that yoga asanas significantly decreased FBG concentrations in Type-2 Diabetic patients after forty days $^{(15)}$.

Lipid peroxidation being an important process of 
oxidative degradation of the lipids increases the oxidative stress in the body. Oxidative stress has been identified and proven to be the root cause of more than seventy different chronic degenerative diseases such as heart disease, cancer, stroke, diabetes, Alzheimer's dementia, Parkinson's disease, macular degeneration and other serious ailments. The significant reduction in lipid peroxidation as recorded after one month yoga therapy might be due to enhancing the antioxidant system of the body.

\section{Conclusion:}

The prevalence of obesity is increasing among all ages,

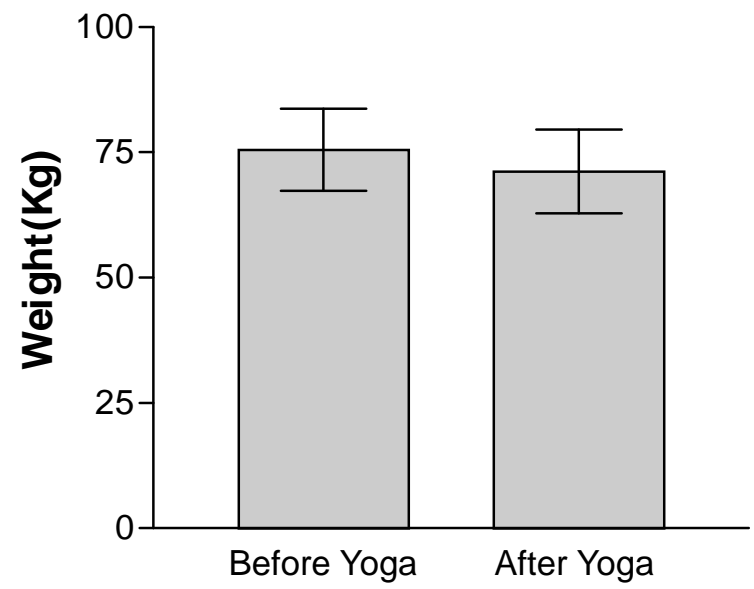

Figure-1: The effect of yoga therapy on body weight. No. of individuals were 40 . There was a significant decline $(p=0.02)$ in body weight after yoga when compared to that before the yoga therapy.

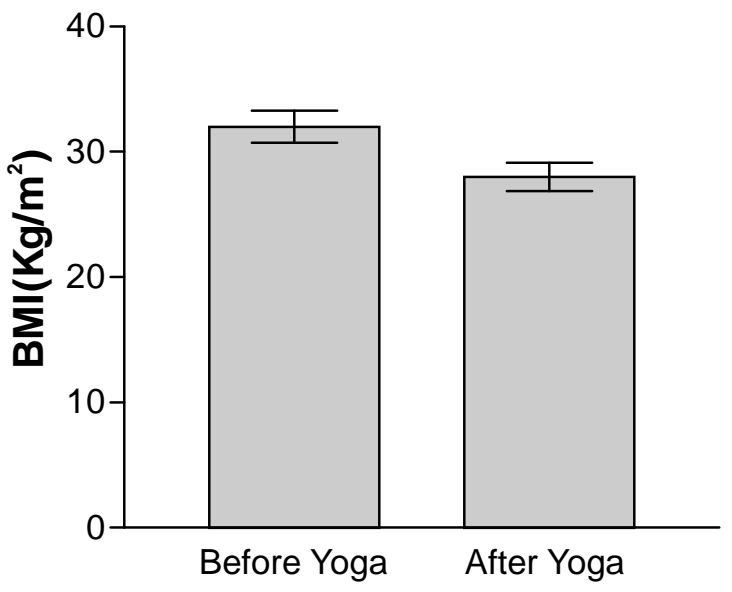

Figure-2: The effect of yoga therapy on Body M ass Index. No. of individuals were 40 . There was a significant decline $(p=0.000)$ in BMI after yoga when compared to that before the yoga therapy. including the elderly. Research has shown that both high BMIs and low BM Is indicate increased morbidity and mortality. Yoga therapy is beneficial in maintaining good health by regulating BMI, Oxidative status by improving the biochemical functions of the body and helpful to overcome the complications of obesity. Hence, from our study, it is concluded that the efficacy of yoga therapy on Body Weight, Fasting and Post Prandial blood glucose, Lipid peroxidation and Total Antioxidant status in obese individuals. This may have direct impact on the use of yoga therapy as a safe therapeutic modality in combating obesity.

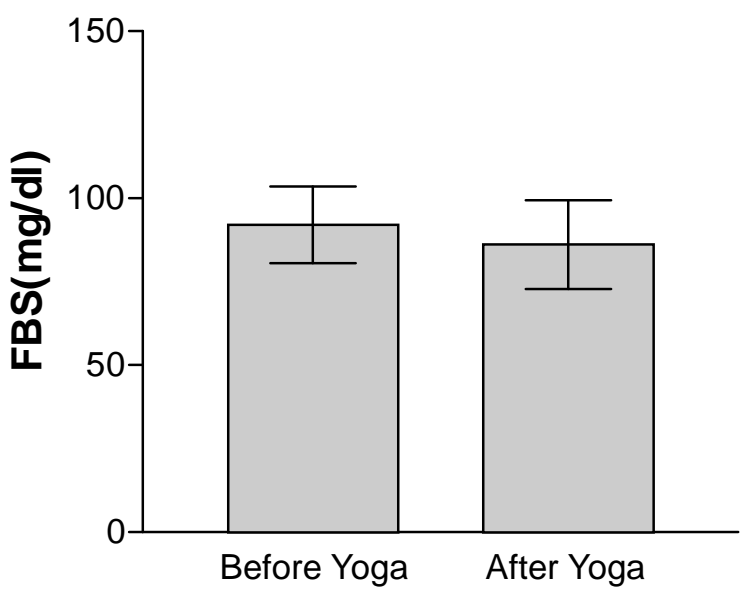

Figure-3: The effect of yoga therapy on Fasting Blood sugar. No. of individuals were 40 . There was a significant decline in FBS $(p=0.03)$ after yoga when compared to that before the yoga therapy.

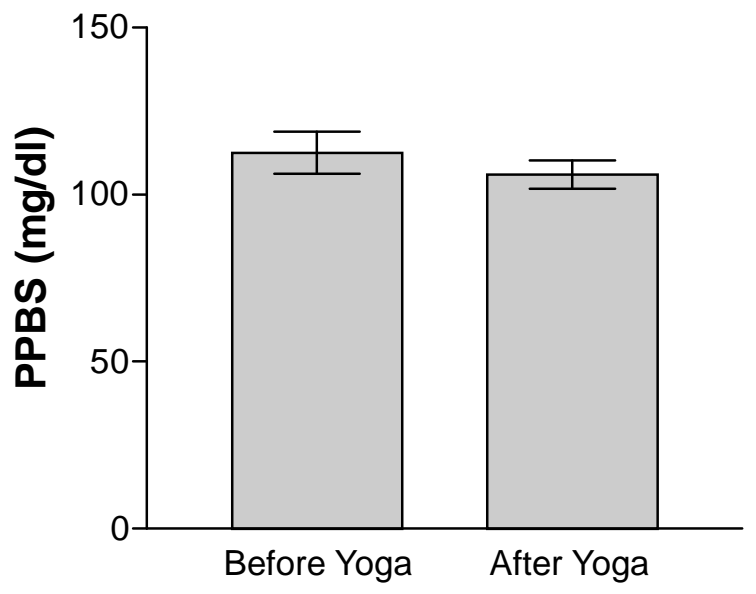

Figure-4: The effect of yoga therapy on Post Prandial Blood sugar. No. of individuals were 40 . There was a significant decline in PPBS $(p=0.000)$ after yoga when compared to that before the yoga therapy. 


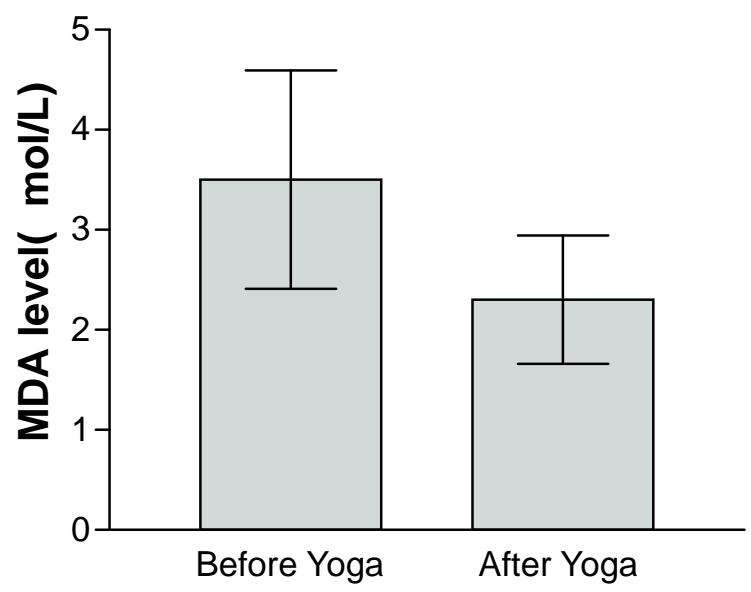

Figure-5: The effect of yoga therapy on Lipid peroxidation (MDA level). No. of individuals were 40 . There was a significant decline in M DA level $(p=0.000)$ after yoga when compared to that before the yoga therapy.

\section{References:}

1. Ross, A.; Thomas, S. The health benefits of Yoga and Exercise: A review of comparison of studies. The Journal of Alternative and Complementary Medicine. 2010; 16(1): 3-12.

2. McCall, Timothy. Yoga as M edicine: the yogic prescription for health and healing: a yoga journal book. Bantam, New York, 2007;17.

3. Syman, Stefanie. The Subtle Body: The Story of Yoga in America. M acmillan, 2010;268-273.

4. Mahboob M, Rahman MF, Grover P: Serum lipid Peroxidation and antioxidant enzyme levels in male and female diabetic patients. Singapore MedJ 2005; 46(7):322-324.

5. Haslam DW, James WP. Obesity. Lancet 2005; 366: 1197-209.

6. Kristal AR, Littman AJ, Benitez D, White E. Yoga practice is associated with attenuated weight gain in healthy, middle-aged men and women. Altern Ther Health M ed 2005; 11:28-33.

7. Allison DB, Fontaine KR, Manson JE, Stevens J, Venially TB. Annual deaths attributable to Obesity in the United States. JAM A 1999; 282 (16): 1530-8.

8. Whitlock G, Lewington S, Sherliker P. Body-mass index and cause-specific

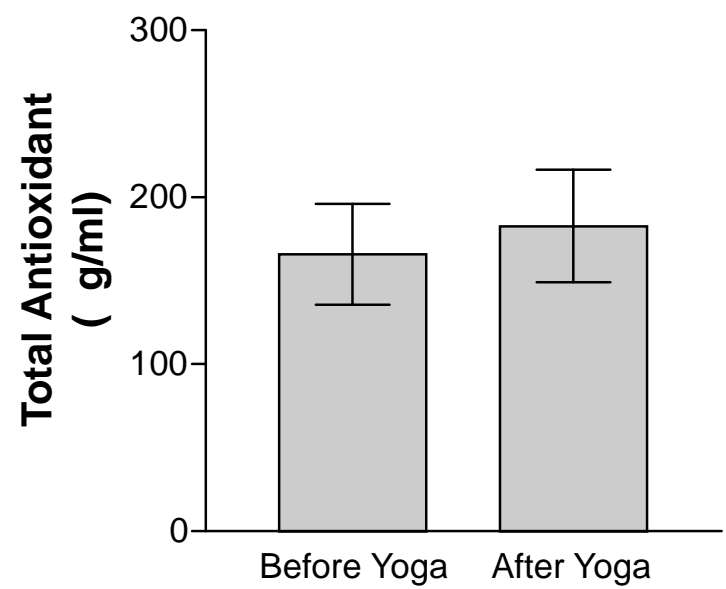

Figure-6: The effect of yoga therapy on total antioxidant status. No. of individuals were 40 . There was a significant increase in the total antioxidant $(p=0.021)$ after yoga when compared to that before the yoga therapy.

mortality in 900,000 adults: collaborative analyses of 57 prospective studies. Lancet 2009; 373 (9): 1083-96.

9. Barness LA, Opitz JM, Gilbert-Barness E. Obesity: genetic, molecular, and environmental aspects. Am. J. Med. Genet.2007; 143A (24): 3016- 34.

10. M okdad AH, M arks JS, Stroup DF, Gerberding JL.Actual causes of death in the United States. JAM A 2000; 291(10):1238-45.

11. Telles S, Naveen VK, Balakrishna A, Kumar S. Short term health impact of a yoga and diet change program on obesity. M ed Sci M onit 2010; 16: 35-40.

12. M clver S, M cGartland M, O'Halloran P. "Overeating is not about the food": women describe their experience of a yoga treatment program for overeating. Qual Health Res 2009; 19:1234-45.

13. Carei TR, Fyfe-Johnson AL, Breuner CC, Brown M A. Randomized controlled clinical trial of yoga in the treatment of eating disorders. J Adolesc Health. 2010; 46: 346-51.

14. M clver S, O'Halloran P, M cGartland M. Yoga as a treatment for binge eating disorder: a preliminary study. Complement Ther M ed 2009; 17:196-202.

15. M alhotra V, Singh S, Tandon OP, Sharma SB: The beneficial effect of yoga in diabetes. Nepal M ed Coll J 2005; 7(2):145-147. 